\title{
NAS REDES DO COMÉRCIO DE RETALHOS
}

Sueli de Castro Gomes*

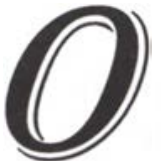

comércio de retalhos e resíduos têxteis está localizado nas ruas do Brás, antigo bairro industrial e operário da cidade de São Paulo'. Esse bairro hoje, concentra um grande número de indústrias e lojas de confecções, que vendem no atacado e no varejo para as "sacoleiras" de todas as partes do Brasil. O comércio de retalhos ${ }^{2}$ nasce nos interstícios das antigas indústrias têxteis e estende-se, posteriormente, para os rejeitos das confecções, as quais fornecem diariamente toneladas de resíduos e retalhos para serem comercializados pelos "retalheiros". Uma parte desses retalhos e rejeitos é comprada por costureiras da
Grande São Paulo e até mesmo por "sacoleiras", sendo que a maior parte dessa mercadoria é enviada para Santa Cruz do Capibaribe - cidade do interior pernambucano, que possui um pólo de confecções de "sulanca" - vestuário de qualidade inferior, consumido, predominantemente, por uma população de baixa renda. $\mathrm{O}$ nordestino de menor poder de consumo passa a ser consumidor do "lixo", do rejeito das confecções do Centro do Sul.

Entre os retalhos de informações, percebemos uma rede de pessoas e mercadorias em torno do comércio de retalhos e resíduos e dessa maneira, inicia-se nossa teia de investigações.

\section{QUEM SÃO OS RETALHEIROS?}

A maioria das pessoas que trabalham nessa atividade é constituída de migrantes nordestinos, podendo ser divididos de acordo com os locais de origem : o primeiro grupo está ligado a uma família da cidade de Ibirajuba - Pernambuco, que tem uma dimensão maior que o segundo grupo, o da família de Iguatu - Ceará; o terceiro grupo, que tem outra característica, é formado por migrantes de Santa Cruz do Capibaribe, também do estado de Pernambuco, e cidades vizinhas. Esse último grupo de migrantes surge seguindo o fluxo desse comércio, pois todos os dias saem caminhões levando toneladas de resíduos e retalhos para Santa Cruz, que serviam, no retorno, de transporte para o migrante, conforme afirma o depoimento de um comerciante:

"Cada caminhão de tecido trazia cinco ou seis".

Assim, a formação desse comércio está também mediada por redes sociais de parentesco ou apadrinhamento, entrelaçadas por redes econômicas e redes territoriais, no caso, as famílias de Iguatu e Ibirajuba. Para entendermos o comércio de retalhos como uma das formas de inser- 
ção de migrantes em São Paulo, encontramos essas redes que nos fornecem elementos para analisar o seu papel como apoio ao migrante que acaba de chegar e, simultaneamente, contribuem para a ampliação desse comércio.

\section{UM POUCO DE SUA HISTÓRIA}

O embrião da atividade do comércio de retalhos aparece, inicialmente, com um pequeno grupo de espanhóis que reaproveitavam o resíduo ou rejeito das confecções do Brás, picotavam o produto em uma máquina chamada a "Máquina do Diabo" e o vendiam como estopa, ou para fazer "enchimento" de colchão, banco de automóvel, pois por volta dos anos 50 não existia a espuma sintética. A partir da década de 60 , o aproveitamento desses resíduos passou a ser feito, predominantemente, por nordestinos, que, no caso, não picotavam, mas revendiam para seus conterrâneos, que aproveitavam para costurar uma confecção mais popular, a chamada sulanca. Até esse momento, os resíduos das confecções eram considerados "lixo" e eram "catados" nas calçadas pelos retalheiros com carrinhos de madeira, como vemos hoje os catadores de papelão e de latinhas. Nos anos 70, esses rejeitos passam a ser comprados e vendidos por um preço mínimo por muitas confecçōes. Hoje existem, aproximadamente, 300 unidades comerciais instaladas no Brás.

Este bairro é uma das áreas de grande concentração de nordestinos em São Paulo. Explica-se, tal fato, por representar o Brás, historicamente, a primeira porta de entrada na cidade: é lá que se encontra a Estação do Norte (atualmente Estação Roosevelt), bem como a antiga Hospedaria do Imigrante - que a partir da década de 1930 passou a receber em maior número os migrantes nacionais, conforme determinavam as políticas migratórias. Posteriormente, foi a influência exercida pela proximidade da também antiga rodoviária da capital paulista, que passa a receber os grandes fluxos de migrantes nordestinos. Cite-se que os primeiros nordestinos que iniciaram o comércio de retalhos chegaram em São Paulo por volta da década de 1950.

\section{O COMÉRCIO}

O comécio de retalhos, criado pelo grupo de migrantes nordestinos, consiste em adquirir das confecções do Brás, o seu rejeito. As peças maiores são chamadas de retalhos, e as menores, de resíduos. Os retalhos podem ser bobinas inteiras de tecidos com defeitos, ou com uma cor fora de moda; enquanto os resíduos são os tecidos que podem já ter sido usados nas confecções e tornam-se sobras. Atualmente, esse comércio que já acontece há mais de 30 anos, compra os retalhos não só das confecções (boa parte controlada por coreanos), mas também das indústrias têxteis. Essas indústrias, no passado, estavam na maior parte concentradas no Brás, onde predomina a indústria de confecções. Hoje, a indústria têxtil se encontra dispersa pelo interior paulista e em outros estados. Assim, essa atividade passa a envolver cada vez mais outros espaços, pois os comerciantes também compram os retalhos das indústrias de Americana, Campinas, Santos, etc, e, ao mesmo tempo, vendem para Goiás, Minas Gerais, Rio Grande do Sul e, principalmente, Pernambuco. Forma-se, assim, uma grande rede de pessoas e mercadorias que tem como ponto de referência ou nó, o Brás. Esse bairro configura o nó que interliga essa rede. Interessa-nos, pois, a definição de nó:

'.... 'unidade físico-espacial', um sistema ambiental-local dotado de sua própria coesão interna, graças à qual ele é capaz de participar de uma coesão mais ampla da rede" (Dematteis, apud Haesbaert, 1995, p.182).

O conceito de rede aparece como uma nova configuração espacial, característica da modernidade. As reflexões sobre o nó e a rede foram importantes para o entendimento das mudanças no Brás: o que era no passado um bairro, território contínuo e coeso, hoje tornou-se um nó da rede, ou um território onde se localiza essa atividade comercial, suporte em que a rede pode se apoiar. A modernidade trouxe a racionalidade do espaço, transformandoo em vértices, arestas, linhas, nós e aglomerados. A rede de migrantes e a rede do comércio de retalhos são redes que se superpõem e têm o seu ordenamento, formam uma malha de homens e mercadorias ou uma malha de múltiplos territórios, senão vejamos:

“... 'um conjunto de nós pertencentes a diferentes redes', 'um conjunto de sujeitos fisicamente coexistentes, mas que pertencem a redes de organização diferentes e cujos interesses podem divergir à escala local (...) Assim o espaço físico de cada cidade seria a sede de vários 'nós' pertencendo a sistemas diferentes, cada um com forma de enraizamento local (rela̧̧ões 'verticais') distintas"(Dematteis. apud Haesbaert, 1995, p. 182).

\section{AS RELAĈ̃ES “FAMILIARES” DE TRABALHO}

Nas relações de trabalho, que identificamos nas unidades de comercialização, o que predomina é a mão-de-obra familiar. Inicialmente, muitos formaram uma "sociedade", em geral constituída por parentes e só depois cada sócio foi adquirindo a sua própria loja. O ganho que a família tem é voltado para os gastos com aluguel, roupa, alimentação, muitas vezes inexistindo a remuneração para os parentes pertencentes à unidade familiar. $\mathrm{O}$ pai é geralmente o "chefe" da unidade, responsabilizando-se em ajudar os filhos a terem o seu próprio negócio. Essa organização interna aparece de forma evidente nas entrevistas de nossa pesquisa, como veremos abaixo:

"Pago não. Eu ajeito eles por aqui. É coisa que se sabe. Essa casa mesmo é deles tudo. Porque eu comprei pra eles trabalhar mais eu. Eu mesmo arrumo um cantinho. Cheguei na Almirante Barroso, ali quando eu comprei essa casa deixei lá uma filha mais velha..." (Sr. Zagaia)."

Poucos se identificam como funcionários, quando o indivíduo se reconhece como tal é porque mantém com o proprietário uma relação de parentesco mais distante tal como: sobrinho, primo, tio. Alguns depoentes destacam a idéia da "ajuda"; a idéia de auxiliar o parente ou conterrâneo está muito presente nesses retalheiros. A solidariedade nas redes aparece nos depoimentos, apontando para a precariedade na área de origem e a possibilidade de ajuda por meio dessa atividade.

Outro aspecto que a rede de relações traz é o aumento progressivo de pessoas 
no ramo do comércio de retalhos e, portanto, o aumento de unidades comerciais. Há uma concentração dessa atividade em determinadas ruas, de forma a atrair o maior número de compradores, tornando esse espaço uma referência; facilita-se, assim, a circulação dessa mercadoria.

O problema a ser investigado é o de entender a contradição que esse comércio apresenta - quanto maior o número de unidades, maior a concorrência no mercado. Paralelamente, entretanto, não havia a preocupação explícita desse comerciante-migrante com a competição, mas sim com o estímulo de inserir o conterrâneo nessa atividade. Como explicar a coexistência da competição desse mercado com o exercício da solidariedade?

A solidariedade está presente entre os migrantes que vieram de uma mesma região com dificuldades de emprego e em precárias condições de vida, encontrandose em São Paulo sem meios de sobrevivência. Esses elementos evidenciam a coexistência dessas duas condições: solidariedade e concorrência. Neste sentido, são significativos os depoimentos a seguir:

"São grande, tem muito lugar para trabalhar: Acho que isso é egoísmo, quem quer só pra si; que adiantava ficar sozinho..." (D. Mira)

“A princípio eu pensava que podia prejudicar, quando chegava um outro concorrente. Mas agora não. Dizem, segundo os comerciantes mais antigos, que até valoriza, tem mais procura, tá assim, todos têm direito a um raio de sol." (D. Marta - comerciante)

"Isso é besteira. Veja bem, o nordestino quando vem do Norte para cá, o maior objetivo dele é tirar o pessoal da desgraça que tá lá... Mas o pessoal que vem do Nordeste, do agreste, eles passam é fome lá, então quando o cara vem para cá - tem um rapazinho que chegou esses dias, é de Itabira. Lá no Nordeste, ele tá com 20 anos e nunca viu uma nota de 50... Então o cara chega aqui, começa a ver dinheiro. Começa a faturar 10, 15, 30.... e fica nisso. Então ele começa a ver dinheiro, demais que depressa ele chama opessoal que tá por lá passando fome, e começa a vir. Aqui nessa rua, João Boemer, se vê uns buraquinhos com 10 ,
15 pessoas lá dentro trabalhando, parece um ninho de rato, todo mundo juntando lá dentro, homem por cima dos trapos, por cima dos resíduos. Então não é uma questão de concorrência, realmente é uma questão de sobrevivência. Então se eu tenho meu irmão que mora lá na casa do chapéu e eu sei que ele tá passando uma situação difícil: 'Vem pra cá!' Outro passando...: 'Vem pra cá que a gente se vira!'. O cara nunca traz pensando que vai ser mais um concorrente, mas pensando que vai ser mais um que tá deixando de passar fome. É isso." (Xique-Xique)

A questão da concorrência para o conterrâneo e parente é descartada, mas observando o dia-a-dia do correntista ${ }^{4}$, vemos que ela aparece claramente, quando ocorre o chamado "furo", isto é, o correntista sabe de uma loja que irá vender retalhos, a um bom preço, mas outro correntista obtém essa mesma informação e rapidamente toma a frente e acaba por fechar negócio. Isso transparece até mesmo nas entrevistas por nós aplicadas em que alguns relatavam ter medo de espião: "tinha muito disso lá". Ou ainda:

"Existe o "furo", eu nunca fiz isso, mas teve muito grandão que já passou na polícia por causa disso (...). O "furo", é por exemplo: eu tenho um negócio por telefone, você sabe, corre logo na minha frente prafechar negócio". ( Francisco)

"... a concorrência entre os corretores é também ferrada, também eles briga Ah! Minha boca, se "furo" minha boca!...." ( Zé)

"Já passa a perna, passa primeiro. Às vezes é avisado antes de você ir na loja. (...), às vezes ganha troco por fora, já pra te avisar antes, entendeu. É assim, quem tá nesse ramo faz tempo tem certas vantagens, já é mais conhecido". ( D. Marta)

\section{NO ESPAÇO DAS REDES}

Existe a presença das redes entre os migrantes que atuam no comércio de retalhos. Póvoa Neto mostra com clareza como essas redes sociais atuam no processo migratório:

“A presença destas redes de contato, cristalizadas ao longo de décadas de migrações, contribui para explicar a inten- sidade dos deslocamentos populacionais mesmo numa situação social em que os diferenciais de renda e de condição de vida se tornam pouco perceptiveis. Tais redes se tornam forças sociais vivas, a estabelecer 'pontes' entre lugares e a permitir $o$ fluxo de informações e pessoas que fizeram da mobilidade geográfica a sua principal estratégia de sobrevivência." (Póvoa Neto: 1997, p.22).

Os primeiros nordestinos utilizaram-se dessas redes para a sua inserção. Inicialmente, como estratégia de sobrevivência e, à medida que a circulação rápida da mercadoria foi possibilitando um rápido acúmulo de capital, também como uma forma de ascenção social, o que reforçou a atração de parentes e amigos conterrâneos para trabalhar no comércio de retalhos.

Em seus depoimentos, os retalheiros apresentavam pessoas, citavam amigos e parentes. Os primeiros retalheiros inseriram seus irmãos, filhos, cunhados, primos. Observamos a circulação de pessoas na atividade comercial a todo instante.

As lojas apresentam um misto de formalidade e informalidade e são um ponto de apoio para os iniciantes. Os antigos retalheiros já estão estabelecidos e trabalham mais com os retalhos, e até mesmo com peças inteiras; esses, com suas lojas, abrem espaços para os recém-iniciados que trabalham com os resíduos. Há uma troca: o antigo retalheiro cede para o recém-chegado, o espaço da loja, informações, contatos, ensinando-o também a trabalhar e, em troca, recebe uma porcentagem sobre as vendas. De acordo com Ramella, os migrantes são atores racionais que perseguem objetivos e mobilizam para tais fins os recursos que têm à sua disposição:

"Estos han sido considerados, a menudo, como recursos relacionales, es decir aquellas relaciones personales que sirven para conseguir información, elegir el destino, insertarse en el mercado de trabajo de la sociedad receptora, etc..." (Ramella, 1995, p.9).

Observamos que a rede social é um mecanismo de mobilização, pois o antigo retalheiro aciona o novo, este por sua vez, aciona o antigo retalheiro para se estabelecer. Esses últimos são mobilizados pelo sonho de ascensão social e de ter a sua pró- 


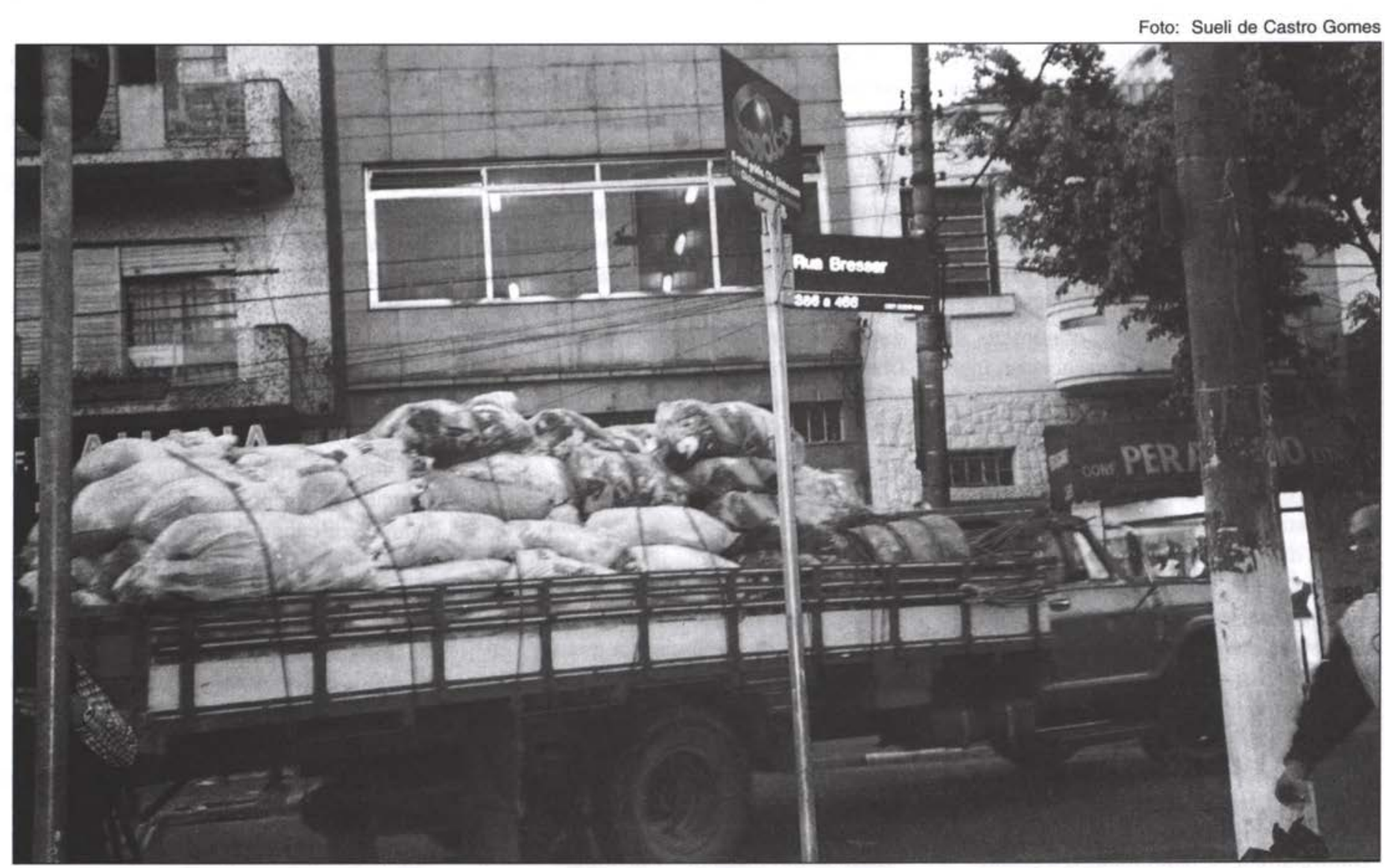

Os caminhôes que levam, diariamente, toneladas de resíduos e retalhos para Santa Cruz do Capibaribe/PE, serviram, também, como meio de transporte para os novos migrantes dessa região.

pria loja. É uma cadeia hierárquica de solidariedade e concorrência que organiza essa atividade comercial.

O conceito de cadeia migratória (Ramella, 1995) é uma parte dos instrumentos metodológicos dos estudos históricos da migração. Durham (1973), na sua obra À caminho da cidade, também aborda essa questão, assim como Woortmann (1984) que traz à luz a perspectiva da unidade familiar e o trabalho no trato dessa questão. Baptista (1998) também utiliza esse conceito da seguinte maneira:

“... são vistas como relações simbólicas de afeto, parentesco, solidariedade. violência. Servem de apoio para o movimento da migração, assim como para o assentamento, engajamento e apropriação do espaço urbano" (p. 11).

Essas redes criam novas formas de sociabilização que, para a autora, podem vir a ser canal de mobilização e enfrentamento das questões sociais emergentes enfrentadas pelos migrantes no competitivo mundo urbano. Baptista vê as redes sociais de solidariedade como tática de resistência e sobrevivência. Em nossa pesquisa, constatamos outra vertente do enfoque das redes que mobilizam, também, para a exploração da mão-de-obra e para o acúmulo de capital individual, além de serem um recurso que o próprio capital mobiliza para a sua reprodução.

Os antigos migrantes que têm um movimento maior em suas lojas contratam como funcionários, migrantes nordestinos com pouco tempo em São Paulo. Em outras unidades encontramos uma relação familiar para o trabalho na loja. Constata-se que algumas lojas são usadas como moradia de famílias inteiras. Esses migrantes têm como trabalho a atividade de separar as peças de retalhos, pelas características que essas apresentam (tamanho, cor, etc.). O trabalho é contínuo e não tem hora para ser realizado, mesmo fechando as portas do horário comercial, eles passam a noite separando os retalhos, sendo que muitas vezes, esse tipo de trabalho não é regulamentado. A relação entre os conterrâneos apresenta uma duplicidade, pois ao mesmo tempo em que aparece a solidariedade e a inserção de parentes e amigos nesse mercado de trabalho, abre-se a possibilidade aos migrantes antigos que estão no topo, de um maior acúmulo de capital, com a mais-valia gerada pelo novos migrantes. É a lógica da acumulação capitalista.

São os dois lados da mesma moeda. Na pesquisa de Baptista, em um outro universo de análise, focalizado nas relações de vizinhança, o estudo das redes sociais de nordestinos na favela de Paraisópolis em São Paulo, privilegia aspectos ligados a:

"A matriz dessas relaçōes são pessoas enredadas por origem, parentesco, dificuldades, amizade, afetividade, desafios, compadrio. Explicitam-se aspectos que mostram o funcionamento e efetividade das redes de atração e inserção no urbano e como elas reproduzem e alimentamo fluxo migratório, assim como a solidariedade entre os chegados, atuação com os que chegam, como e quem atua junto aos migrantes. As redes sociais apresentam- 
se, então, como táticas de produção e reprodução, econômica e cultural que unificam a vida anterior e atual. ..." (Baptista, 1998, p.24)

Para a autora, os migrantes são atores interconectados, que possuem uma identidade comum (cultura, classe social, temporalidades). Eles se apóiam no passado (área de origem), no presente (o convívio) e no futuro (seus sonhos). Ocupam os mesmos espaços e se socializam. As redes sociais são elos fortes que se manifestam de diferentes formas: solidárias, conflituosas, visíveis, latentes e estratégicas.

No universo de análise do mundo dos retalhos esses aspectos evidenciam-se dialeticamente relacionados à competição no centro urbano permeado pelas relações capitalistas de produção.

\section{OS LIMITES DA REDE: ENTRE A SOLIDARIEDADE E A CONCORRÊNCIA}

A pesquisa sobre o comércio de retaIhos pôde constatar nos depoimentos, conflitos que ocorrem nas relações de negociações entre os migrantes retalheiros. Observamos que, em alguns aspectos, a conterraneidade perde o seu significado e a rede de solidariedade ocupa uma posição secundária. Uma das formas de mostrar a desconfiança, nessas relações, entre os nordestinos, é a exigência na forma de pagamento pela mercadoria, que é, sempre, à vista. Normalmente, o negócio a ser realizado envolve um pequeno valor, outra justificativa para essa forma de pagamento. A confiança somente aparece entre os antigos conhecidos de um mesmo local de origem e seus parentes; fora isso, a negociação ocorre com cautela; não é a origem que define a confiança, mas o tempo de amizade entre as partes, podendo, essa também, ser abalada:

"Já me roubaram muito aqui nesse São Paulo, é um lugar..., cheque sem fundo, ladrão aqui. Chegou um aqui da minha terra, que morava aqui há muito tempo, comprou umas dizias e me enganou... E outro ladrão aqui me roubou aqui naquela rua ali. Comprava um retalhozinho a ele - 'Zeca tem um retalhozinho? E o infeliz, dono de loja, ainda, chegou aqui né, ladrão, que nem nosso Senhor se livrou da falsidade, como diz o povo... Eu conhecia o homem há muito tempo, eu pegava resíduo na loja dele, um ladrão, conheço o nome daquela peste". ( $\mathrm{Sr}$. Zeca).

Miguez (1995) avalia os estudos das redes sociais como uma recuperação valiosa porque é capaz de "mostrar as brechas e espaços abertos pelas completas incoerências de todo o sistema". Essas "incoerências", ao denominarmos de contradições, aparecem nas relações dos retalheiros que, ao mesmo tempo, são o ponto de apoio de outros migrantes que se inserem na atividade de uma forma solidária. Essa relação também é uma forma de acúmulo da mais valia produzida pelo conterrâneo. Assim, há os dois viéses dessa condição que, em alguns momentos, são rompidos por conflitos que, muitas vezes, não foram explicitados nessa trama de relações. Muitas pesquisas tratam essas redes com estigmas de família modelo, ou o conterrâneo solidário, esquecendo as relações conflituosas em que a conterraneidade nem sempre é sinônimo de solidariedade.

\section{CONCLUSÃo}

O comércio de retalhos amplia-se à medida em que as redes sociais atuam, servindo de apoio, principalmente, com as informações próprias desse mercado. Então, para o grupo de migrantes que estudamos, as redes têm servido para definir os seus itinerários e a sua inserção no urbano e no mercado de trabalho. Desse modo, a ampliação do comércio de retalhos redefine a configuração espacial, na qual uma rede de mercadorias e de pessoas se confundem. Podemos perceber como o processo econômico incorpora as redes sociais para a reprodução e ampliação do capital.

\section{* Sueli de Castro Gomes é Mestranda em Geografia Humana - Departamento de Geo- grafia da FFLCH-USP.}

\section{NOTAS}

1. Este artigo é parte da pesquisa em andamento sobre o comércio de retalhos como uma estratégia de inserção do migrante em São Paulo, que está sendo desenvolvida no curso de mestrado em Geografia Humana do Departamento de Geografia da USP.
2. Esse comércio acaba se tornando uma das formas de representação da interdependência econômica entre as regiōes Nordeste e Centro-Sul, tratada por Oliveira (1981) e Singer (1974) em seus estudos.

3. Todos os nomes usados nos depoimentos são fictícios.

4. Correntista é uma denominação dada pelos retalheiros aos intermediários, os quais compōem uma categoria que se formou no comércio de retalhos.

\section{REFERÊNCIAS BIBLIOGRÁFICAS}

BAPTISTA, Dulce M. T.

(1998) Nas Terras do "Deus Dará"Nordestinos e suas redes sociais em São Paulo. Tese de Doutoramento em Ciências Sociais. São Paulo, PUC (mimeo).

\section{DEMATTEIS, G.}

(1992) Les systèmes urbaines en réseau: temps du développement. Colóquio Le temps des villes. Paris, EHESS. (datil.)

DURHAN, Eunice

(1973) À Caminho da Cidade. São Paulo, Ed. Perspectiva.

HAESBAERT COSTA, Rogério

(1995) "Desterritorialização:entre as redes e os aglomerados de exclusāo". In: Geografia: Conceitos e Temas. Rio de Janeiro, Bertrand Brasil, p.165-205.

MARTINS, José de Souza

(1998) "O problema das migraçōes no limiar do Terceiro Milênio". In: O Fenômeno Migratório no Limiar do $3^{*}$ Milênio. Petrópolis, Ed. Vozes, p.19-34.

MIGUEZ, Eduardo

(1995) "Microhistoria, Redes Sociales e Historia de Las Migraciones: Ideas Sugestivas y Fuentes Parcas". In: BJERG, Maria y OTERO, Hernán (org.) Inmigracion y Redes Sociales en La Argentina Moderna. Tandil: CEMLA-IEHS, p.23-34.

OLIVEIRA, Francisco de

(1981) Elegia para uma Re(li)gião. Rio de Janeiro, Paz e Terra, $3^{\mathrm{a}}$ ediçāo.

PÓVOA NETO, Helion

(1997) "Migraçōes internas e mobilidade do trabalho no Brasil atual - Novos desafios para a análise". In: Experimental, $n^{\circ} 2$, pp. 11-24.

RAMELLA, Franco

(1995) "Por un uso Fuerte Del Concepto de Red en Los Estudios Migratórios", In: BJERG, Maria y OTERO, Hernán (org.) Inmigracion y Redes Sociales en La Argentina Moderna. Tandil: CEMLA-IEHS, pp. 9-21.

SINGER, Paul

(1974) Desenvolvimento Econômico e Evolução Urbana. Companhia Editora Nacional, São Paulo, pp.19-79.

WOORTMANN, Klaas A. A. W.

(1984) "A Familia Trabalhadora". Série Antropologia, $\mathrm{n}^{\circ} 40$, Brasilia, (mimeo). 